\title{
The influence of yoga therapy on anxiety
}

\author{
Lindsay Clark', Stephen Edwards ${ }^{2}$, Jabulani Thwala ${ }^{3}$ and Patricia Louw ${ }^{4}$ \\ University of Zululand Psychology and English Departments \\ Iclarke@pan.uzulu.ac.za,sdedward@telkomsa.net, jtwala@pan.uzulu.ac.za, plouw@pan.uzulu.ac.za
}

\begin{abstract}
The stressful lifestyles that accompany modern living generate levels of anxiety that become a major concern in society. Psychopharmacological medication and psychotherapy for anxiety is expensive for government health departments as well as for individual consumers. Although the value of yoga as a beneficial and cost effective therapy for anxiety has long been advocated, there have been very few well designed scientific studies in this regard. Therefore the aim of this research was to evaluate the effectiveness of yoga therapy on anxiety perceptions and experiences. The research hypothesis that yoga could decrease such anxiety was investigated by comparing two groups, an experimental group of 18 participants that practised yoga and a control group of 19 participants that did not practise yoga, over a duration of three months, The research design included quantitative and qualitative research methods. Quantitative results from the Beck Anxiety Inventory (BAl) indicated that, although regular yoga therapy was associated with significant decreases in anxiety perceptions over time, these changes were not significant when compared with the control group. Therefore, no causative inferences can be made. Qualitative findings from thematic content analysis of participants' experiences suggested meaningful relief from anxiety over time, especially with regard to such themes as physicality, contentment, relaxation, breath control, mindfulness, transcendence and spirituality. Although further randomised controlled studies with larger samples are needed, this research provided some systematic evidence for yoga therapy as a significant and relatively cost effective intervention for anxiety reduction.
\end{abstract}

Key Words: Yoga, therapy, anxiety, stress.

\section{Introduction}

Anxiety is endemic to human existence (Khan, Singh \& Salman, 2005). It may be defined as the experience of an unpleasant yet vague sense of apprehension. This is accompanied by autonomic symptoms such as a headache, perspiration, palpitations, tightness of the chest, stomach discomfort and restlessness. Modern scientifically orientated treatment, which typically involves psychopharmacology and/or psychotherapy, usually of the cognitive behavioural type, may be effective in the short term, but is limited, expensive and relapse rates are high (Sadock \& Sadock, 2007). Although the value of yoga as a more holistic, integral, beneficial and cost effective therapy for anxiety has long been advocated, there have been very few well designed, scientific studies in this regard (Forbes, Akturk, Cummer-Nacco, Gaither, GotzHarper \& Hartsell 2008; Shankar, 2006; Streeter, Whitfield, Owen, Rein, Karri, Yakhkind, Perlmutter, Prescot, Renshaw, Ciraulo, \& Jensen (2010); Wilber, 199I, 1998). Therefore the aim of this research was to evaluate the effectiveness of yoga therapy on anxiety perceptions and experiences.

From a modern scientific perspective, anxiety may be seen to be closely related to lower levels of the neurotransmitter, gamma-aminobutyric (GABA) in the brain (Forbes et al., 2008). Research by Streeter et al., (2007) has found that practising yoga has an association with increased neurological levels of GABA. Furthermore this latter study indicated that yoga practice resulted in greater improvement in mood and greater decreases in anxiety levels, in comparison to the metabolically matched walking intervention (Streeter et al., 2010). Such findings led to the present study research hypothesis of the effectiveness of yoga practice on anxiety.

The basic principles of yoga therapy

The general principles that guide yoga therapy are based on the ancient Yoga Sutras that were devised and codified by the Indian sage Patanjali approximately 2000 years ago. These principles are referred to as the eight-fold path of yoga, or the eight limbs of yoga. This was designed to create a sense of awareness that flows from the external universe to the internal self, while maintaining an awareness that the individual holistically is one (Atman) with the universe. Yoga embodies the Universal Spirit of Brahman (Wilber, 198I). The eight-fold path of yoga is constituted by the following: Yamas; universal morals and guidelines for engaging with others; Niyamas; personal disciplines; Asanas, bodily postures and attitudes; Pranayama, control and regulation over breathing; Pratyahara, withdrawing one's senses from the world and redirecting the senses inward to create awareness; Dharana, concentration on one's attention and intention; Dhyana, development

I. Lindsay Clarke, is a masters counselling psychology intern at the University of Zululand

2. Stephen Edwards, PhD, DEd, is an Emeritus Professor and Research Fellow in the Department of Psychology, University of Zululand, South Africa

3. Jabulani D. Thwala PhD is an Associate Professor and Acting Head of the Department of Psychology, University of Zululand, South Africa

4. Patricia Louw is a Lecturer in the Department of English, University of Zululand, South Africa 
and cultivation of inner awareness through meditation; and Samadhi, spiritual absorption and union with the Divine (Shankar, 2006). Apparent in the eight limbs is a hierarchical progression from the physical elements of life, to the mental, or conscious component, and through to the spiritual, where all components integrate into a unified state of being and/or consciousness.

\section{Methodology}

Design

The study used a mixed approach, in a quasi-experimental design with both quantitative and qualitative data collection methods, which required repeated measures ANOVA and thematic content analysis as data analysis research techniques. Anxiety was quantitatively assessed using the Beck Anxiety Inventory (BAI) (Beck \& Steer, 1993), which is a standardised anxiety scale used to measure individuals' levels of perceived anxiety. A qualitative questionnaire was used to assess the experimental groups' anxiety experiences in relation to their yoga practice.

\section{Ethical matters}

With appropriate departmental ethical clearance, informed consent and guaranteed confidentiality, data was collected from an experimental group of yoga practitioners as well as a control group of students. All participants were informed as to the nature of the research, which involved pre-testing and post-testing, assured that they should participate only if they were happy and willing to do so, assured that they could withdraw from the study at any time and were requested not to write their names on any questionnaires handed in.

\section{Procedure}

Qualitative data was collected from the experimental group prior to the yoga therapy intervention. Quantitative data was obtained from the experimental group and the control group in the pre-test session on February 2010 and post-test session on May 2010. This was succeeded by the data analysis.

\section{Participants}

Participants in the experimental group were selected according to non-random convenience sampling. These 19 participants comprised selected practitioners of yoga from Zululand and the Eastern Cape, who practised yoga at least twice a week for the three month duration of the research project. Participants in the control group were also chosen according to non-random convenience sampling. This sample of participants who did not practise yoga for the duration of the research period was obtained from the counselling and clinical psychology masters class at the University of Zululand in KwaDlangezwa. Some of their family members were included in order to increase the sample size.

Demographically, the experimental group comprised 18 participants, 16 females and 2 males, with I 5 English language speakers and 3 Afrikaans language speakers. These participants had a mean age of 41.6 , an age range of 26 to 59 years old and an average of 15.8 years of formal education. The control group comprised 19 participants, II females and 8 males, with 10 African language speakers, 6 English language speakers and 3 Afrikaans language speakers. These participants had a mean age of 32.7 , an age range of 22 to 59 years old and an average of 17.7 years of formal education.

Data collection

In addition to the abovementioned biographical information, before and after the yoga intervention, pre-test and posttest, quantitative data was collected from both the experimental group and the control group in the form of the Beck Anxiety Inventory (BAI) (Beck \& Steer, 1993). The experimental group also completed a qualitative questionnaire which "attempted to understand people's perceptions, perspectives and understanding of a particular situation" (De Vos, Strydom, Fouche \& Delport, 2008, p.264). In this case, the phenomenological data explored the yoga practitioners' perceptions and experiences of yoga. Of particular interest was their experience and perception of the influence of yoga therapy on anxiety.

Quantitative instrument

The Beck Anxiety Inventory (BAI) (Beck \& Steer, 1993) is a standardised self-report 2l-item inventory designed to measure the severity of anxiety. Although the BAl has not been standardised on the South African population (Pillay, Edwards, Sargent \& Dhlomo, 200I), the scale has established good internal consistency and reliability, as well as high concurrent validity with other measures of anxiety. It has also demonstrated the ability to differentiate anxiety disorders from other non-affective psychiatric disorders (Rybarczyk, DeMarco, DeLaCruz, Lapidos \& Fortner, 200I).

Qualitative questionnaire

A qualitative questionnaire was developed to assess the experimental group members' experiences and perceptions towards yoga, and particularly their understanding and feelings towards the influence of yoga therapy on anxiety. The Inkanyiso, Jnl Hum \& Soc Sci 20I I, 3(I) 
questionnaire was rationally designed and prepared in a way that it gradually extended the enquiry of the participants' perceptions of yoga therapy.

\section{Data analysis}

The quantitative data from the BAI was analysed using the Statistical Package for the Social Sciences (SPSS). The researcher consulted a statistician to assist in the interpretation of the results from the quantitative outcomes obtained. Statistical analysis involving ANOVA with repeated measures and $t$ tests was performed within and between the experimental and control groups. Thematic analysis was used to analyse and interpret the qualitative data. Through this process the subject of the enquiry was examined by systematically identifying salient themes and common categories by reading and re-reading the scripts (Boyatzis, 1998); (De Vos et al., 2008).

\section{Results and discussion}

Quantitative findings

Table I below reflects a summary of the means and standard deviations of the results of the Beck Anxiety Inventory.

Table I Summary of the means and standard deviations of the Beck Anxiety Inventory

\begin{tabular}{lcccccc}
\hline \multicolumn{1}{c}{ Group } & Age & Gender & Education & Language & TI & T2 \\
\hline Control & $32.7(14.0)$ & $0.4(0.5)$ & $17.7(2.7)$ & $1.7(1.1)$ & $8.9(5.3)$ & $14.4(9.3)$ \\
Experimental & $41.6(11.4)$ & $0.1(.03)$ & $15.8(2.5)$ & $0.8(0.4)$ & $9.4(8.5)$ & $6.3(6.6)$ \\
Total & $37(13.3)$ & $0.3(0.5)$ & $16.8(2.7)$ & $1.3(0.9)$ & $9.2(7.0)$ & $10.7(8.9)$ \\
\hline
\end{tabular}

Table I shows a summary of the means and standard deviations (in brackets) for the 19 control group members and 18 experimental group members with regard to the variables of age, gender, education, language, pre-test (TI) and post-test (TI) self-perceptions of anxiety as measured in terms of scores on the Beck Anxiety Scale. For all analyses, probability level was set at the conventional .05 level of significance.

Analysis of variance with repeated measures indicated no significant differences between the experimental and control groups with regard to any change in perceived anxiety over time as assessed on pre-test (TI) and post-test (TI) measures of Beck's Anxiety Scale ( $F=2.52 p=.0 .12)$. However, results are clearly in the hypothesised direction, reaching the $12 \%$ rather than the $5 \%$ level of significance. Examination of Table I indicates that this change was associated with both an increase in perceived anxiety in the control group and a decrease in perceived anxiety in the experimental group. Furthermore paired sample $t$-tests confirmed significant decreases in anxiety in the experimental group $(t=2.55, p=.02)$ as well as significant increases in anxiety in the control group $(t=2.89, p=.0 \mathrm{I})$.

Therefore although the main research hypothesis could only be partially supported, that is, regular yoga therapy was associated with significant decreases in anxiety over a period of three months, these changes did not quite reach the accepted $5 \%$ significance level when compared with a control group. Thus no causative inferences can be made. However, in view of the relatively small numbers and trends in the expected direction, it seems quite likely that further experimental interventions with larger numbers, over a longer period, may be associated with more significant betweengroup changes. The fact that 14 individual members of the experimental group's anxiety scores decreased or stayed the same whereas only 4 of the control group's anxiety scores decreased or stayed the same supports this prediction in future research with larger numbers of participants.

The repeated measures analysis of variance was performed with age, gender, education and language as covariates. This analysis revealed significant inter-group results for age $(F=8.2, p=.008)$ and education $(F=5.5, p=.03)$. These findings indicate that older and more educated participants' anxiety scores decreased significantly more than those of younger and less educated participants. In view of the small numbers, and the strong possibility that this particular type of yoga intervention was differentially biased towards benefitting older and more educated participants, further evidencebased research is needed in order to make any firm or generalised inferences in this regard.

Thus, in terms of these quantitative findings, the proposition that participation in yoga therapy would be associated with a reduction in anxiety levels over the three month test period was only partially supported. It did not show a statistically significant reduction in anxiety levels in the experimental group, as compared to the control group. The variances did, however, indicate an increase in perceived anxiety in the control group and a decrease in perceived anxiety in the experimental group. These trends may be associated with a number of factors, including the relatively small size of the two samples and the fact that the control group was "loaded" with Masters' students, who may have felt greater levels of anxiety as their course progressed. 
Qualitative findings

In the qualitative questionnaire, the participants were asked to share their experiences of the influence of their yoga practice on anxiety.

Although all participants reported that they experienced anxiety relief through the medium of their yoga practice from different perspectives, recurrent themes were noticed throughout the responses. It was evident that numerous participants experienced a sense of relief from physical symptoms as a result of their regular yoga practices.

Physical manifestations.

The following responses represent the experimental group's experiences and reflect on some of the physical manifestations of yoga:

- "I often gather my anxious feelings in my digestive system. Yoga has physically made a big impact on my anxiety by reducing it."

- "Regular practice certainly has a positive effect on my anxiety levels. I have also had medical/physical reasons for my anxiety. Yoga - particularly forward bends - seem to lower my heart rate."

- "A forward bend class will remove any anxiety I may have had at the start of the class"

- "My entire nervous system has a chance to recover during the session."

- "Yoga helps all the organs, glands etc. to function better."

- "I have also taught students that have been very anxious or stressed at the beginning of the class due to depression, bipolar, loss of a family member etc. By the time they have completed the class: their eyes are brighter, their skin is softer/ relaxed/ less frown marks, they walk taller and sometimes even with a spring in their step. They seem more interested and receptive to the other students interacting with them; there is a lightness about them."

It is evident from the anecdotal responses quoted above that these participants have had positive experiences from their yoga practice, in terms of an effect on their anxiety levels in relation to their physical symptoms. Research by Smith, Hancock, Blake-Mortimer \& Eckert (2007) supports the first quoted response above, suggesting that standing postures and supine (lying down) postures assist in improving digestive functioning in the body.

Two participants mentioned that incorporating forward bends into their yoga practice routine benefits them by means of lowering the heart rate and decreasing perceived anxiety respectively. Literature suggests that forward bends are known to promote calming and soothing effects within the body (Smith et al., 2007). Da Silva, Ravindran and Ravindran (2009) suggest that controlled breathing has a positive effect on the autonomic functions within the body, such as heart rate, emotion, stress and cognition. This contention is borne out by respondents who said that yoga practice assists in letting the nervous system recover, and maintaining good functioning of the organs. Literature supports the participants' experiences. According to Forbes et al. (2008), yoga calms and balances the nervous system, and Young (1988) maintains that yoga techniques tone the organs and calm the emotions. Mastering pranayama techniques and asanas are integral to the practice of yoga, and so form the link between body-mind integration that is central to yoga (Chopra \& Simon, 2004).

\section{Contentment}

Some of the responses pointed to feelings of well-being and health after their yoga class. Chopra and Simon (2004) explain that the central purpose of yoga is being aware of the integration of the environmental, physical, emotional, psychological and spiritual aspects of life. This accords with the observation of a teacher participant, that after yoga classes she notices a difference in the physical being of her students. Through the medium of yoga, this teacher participant appears to convey to her students this multidimensional aspect of yoga. The description of the physical state of her students conveyed a feeling of contentment.

According to Chopra and Simon (2004), contentment or santosha is an essential component of niyama; Patanjali's second branch of yoga. According to Patanjali, contentment is a complete acceptance and awareness of the present moment (Chopra \& Simon, 2004). This significant component of the practice of yoga, consistent with the research hypothesis, evidenced itself as a salient theme within the participants' experiences of yoga and relief from their perceived anxiety, as indicated in the following responses:

- "Yoga brings me down to earth. It helps me to stop thinking about small things that worry me and I can focus on the immediate moment."

- "My mind has to focus on something else."

- "Fully focussing on my postures ... I'm forced to keep focus."

- "I would say yoga is essential for anyone suffering from anxiety. It brings you back to the moment and helps you think clearly."

- "Yoga helps me to control my anxiety concerning future events helping me to focus on the present"

- "Yoga is a form of meditation because you cannot think about your problems while focussing on postures, breathing and

Inkanyiso, Jnl Hum \& Soc Sci 20I I, 3(I) 
balance. It therefore allows a respite from the worries of the world."

The common factor in these responses was a focus on the present moment and the experience of being in the "here and now." As stated above, this yogic experience of being fully present is fundamental in Patanjali's second branch of yoga, niyama, under the category of santosha or contentment.

\section{Relaxation}

As a means of managing anxiety, the participants stated that through yoga practice they are able to experience relaxation and calmness. The following responses revealed the theme of yoga being a means of relaxation:

- "Yoga has physically made a big impact on my anxiety, it helps me to feel more relaxed and in control."

- "After just one session I feel more relaxed, I am calmed by knowing I have consistent 'rest' in my busy schedule. During stressful moments in my day I enjoy knowing I will relax at yoga."

- "Relaxation time cures the anxiety for lasting effect until a good couple of hours after class."

- "I don't think I suffer from anxiety but am definitely a lot calmer that I can remember."

- "Regular practice certainly has a positive effect on my anxiety levels. Relax(es) and make(s) me feel less anxious."

- "Yoga practice has a calming effect, however it requires constant practice, discipline and determination."

These responses indicate that yoga practice assists its practitioners in terms of feeling a sense of calmness and experiencing relaxation. According to Chopra and Simon (2004), yoga embodies a sense of calmness about it, and through yoga practitioners are able to remain calm, centred and in touch with their environment. Forbes et al. (2008) suggest that yoga has the ability to promote mindfulness within the individual, and through this, calmness and balance are instilled within the practitioner. From the foregoing, it can be seen that relaxation comes through as an important outcome and benefit of yoga.

Breath control

Patanjali maintains that pranayama (the control and regulation of breathing) forms an integral component of yoga practice. It was therefore not surprising that this featured as a recurrent theme in the participants' experiences of anxiety. The following responses were noted in relation to pranayama and anxiety.

- "I have found that when I am in a stressful situation e.g. going to the dentist, yoga breathing and relaxing helps me to get through the unpleasantness of the dental procedures."

- "Breathing techniques are a simple way to calm mental activity at any time and in any circumstance throughout our daily lives."

- "Anxiety influences my breathing."

- "Without breathwork, yoga would simply be a gymnastics practice. Our breath influences our state of mind - a stressed, agitated mind is reflected in short, irregular breathing."

As stated by one of the participants, yoga would be just another physical exercise if it were not for the breathing techniques. It is the element of pranayama that distinguishes yoga from other physical activities. One of the participants stated that a stressed, anxious mind is reflected in irregular breathing. This response is affirmed by numerous sources. Gilbert (1999) suggests that one of the fundamental principles of pranayama, is that the nature of one's breath is a reflection of one's state of mind. Hence a distressed mind is associated with irregular breathing, while a calm mind leads to smooth and balanced breathing. Chopra and Simon (2004) agree that when the mind is still, the breath may remain steady, but when the mind is not at rest, then the breath becomes uneven. This concept of mind-breath interaction has been accepted by yogis and philosophers alike for centuries. Kariba Ekken, a seventeenth-century mystic, stated that "before attempting anything, first regulate your breathing on which your temper will be softened, your spirit calmed" (lyengar, 1982, p. 44).

Two of the participants mentioned that they use the techniques of pranayama in managing daily-life anxiety-provoking situations such as going to the dentist. Chopra and Simon (2004) promote yoga as a lifestyle, and the incorporation of yogic principles, such as pranayama, into daily living. Forbes et al. (2008) agree, and suggest that pranayama techniques translate into the ability to practise mindfulness "off the mat." Thus the 'life force' of pranayama forms an integral part of yogic life practice and can reduce anxiety in stressful life situations. The above examples of relaxation and breath control also imply mindfulness and transcendence as discussed below. 


\section{Mindfulness}

According to Chopra and Simon (2004), this fragrance of present moment awareness arises when one surrenders the need for control, authority and approval from others. Hence one's present moment focus or contentment is reflected in the absence of dependence on power, sensation and security. "Through the practice of yoga, your experience of the present moment quiets the mental turbulence that disturbs your contentment - contentment that reflects a state of being in which your peace is dependent of situations and circumstances happening around you" (Simon \& Chopra, 2004, p.37). The experience of contentment, offered by yoga practice, allowed the participants to relinquish their thoughts and worries concerning the past and future, and it required them to focus purely on the present moment.

Acknowledgement of the present moment, during the participants' yoga practice, talks to the experience of witnessing awareness. This is reflected in Patanjali's seventh branch of yoga; dhyana. According to Chopra and Simon (2004), dhyana is the cultivation of a sense of awareness, where, in the midst of life's changing and unpredictable circumstances, it is the individual's being, the conscious soul that witnesses these goings on. Thus, through focussing on the present moment during their yoga practice, the participants were able to be centred, aware and conscious of their state of being.

\section{Transcendence}

This state of being "centred" in the moment during yoga practice, as means of transcending perceived anxiety, should be viewed from an integral perspective. According to Wilber (198I), the present moment may be understood as a noboundary moment. This is because the past and the future do not exist outside of this moment, therefore there are no boundaries within this moment; nothing came before it and nothing comes after it. Thus, one never experiences a beginning to this moment, and one never experiences an end to it. It has been said by the Platform Sutra that

in this moment there is nothing which comes to be. In this moment there is nothing which ceases to be. Thus there is no birth-and-death to be brought to an end, thus the absolute peace in this present moment. Though it is at this moment, there is no boundary or limit to this moment, and herein is eternal delight (Wilber, 1981, p.69).

In the above quotation, the author conveys that awareness floats in the eternal present moment, where all time is embraced. One is not really bound by the past and future, because in essence the present encapsulates the past and future (Wilber, 198I). The participants' responses encapsulated this state in a simple manner, in the way that, through their yoga practice, they are able to be fully aware and experience the present moment.

In summary, Wilber (2000) suggests that awareness of the present moment enables one to dissolve boundaries and promote unification of facets of self and open up the field of awareness, moving away from restricting parts of life. This was conveyed through the participants' responses, that it was the experience of being focussed in the present moment that made their yoga practices sacred to them.

\section{Spirituality}

In terms of understanding the experience of the influence of yoga practice on anxiety, one of the participants, welltravelled on the yogic journey, provided a unique explanation that was different from the other participants' perspectives on anxiety. The following response was provided:

Anxiety is rooted in fear. The fear of death is a primordial fear - not only death of the body, but also death of the ego.

The ego exerts great effort to remain in control of our realities and creates disassociation between mind, body and spiritual self. Yoga, on the other hand, creates a link between our mind, body and spirituality. Yoga is the antithesis to the ego. Yoga allows a person to reconnect all aspects of themselves in a way that results in a reality of wholeness. Yoga also helped me to realise that I am not this body and that, as a spiritual being, I will actually never die. The fear of death is simply a fear of the body dying. When one realises that we are not defined by our physical reality, then one is free of the anxiety that this physical reality will end.

In yogic terms, this response evidences an advanced appreciation of the author's being and someone whose selfperception is greatly influenced by yogic philosophies. That "anxiety is rooted in fear" shows an appreciation of the distinction between fear and anxiety. Sadock and Sadock (2007) convey that fear is an individual's response to a known, external threat, while anxiety is a response to an unknown, internal threat. The notion of the development of a higher deeper self through "death" or transcendence and inclusion of "ego" structures, understanding of the integrative effect of practice on body, mind and spirit, and belief in the principles of yoga seem to have provided the respondent with deep psychological and philosophical insights and realisations.

This resonates with Chopra and Simon (2004), where in yogic terms the ego is referred to as the ahankara. The ego is essentially one's self-image, and the way that the individual projects who he/she is to him/herself and to the people around him/her (Chopra \& Simon, 2004). This respondent's perspective also speaks to Patanjali's eight limbs of yoga, where the eighth limb, Samadhi, is the antithesis of the ego. Through experiencing Samadhi, one achieves an unbounded Inkanyiso, Jnl Hum \& Soc Sci 20I I, 3(I) 
sense of awareness, a reality that is beyond individuality, a sense of being One with the universe (Chopra \& Simon, 2004). According to Wilber $(1998,2000)$, this state may be defined as Atman-Brahman; being One with the Universal Spirit. When this state of consciousness is achieved through regular yoga practice and meditation, one's internal point of reference is transferred from ego to soul to spirit and fear and anxiety cease to exist. (Chopra \& Simon, 2004)

The participant professed that, through yoga, he has been able to rise above the ego. Furthermore, the participant reflects Chopra and Simon's view that yoga creates a union between the mind, body and spirit. It has been through the medium of yoga that the participant has realised that one is not one's physical body, but a spiritual being in a human body. This perspective is also conveyed by Chopra and Simon (2004). This participant's perspective of the fear of death as purely a fear of the body dying, and that one is not defined by one's physical body, suggests that he has travelled far down the yogic road and has a sophisticated grasp of the discipline. Reverting to the question of whether yoga offers the particular respondent a relief from anxiety, it would seem that he has a sound philosophical basis for dealing with anxiety. He seems to be close to Wilber's place of arrival where there is unity consciousness, where there is a holistic awareness of no-boundary and the awareness that one becomes involved in spiritual practice because one has seen the light, that enlightenment is practice (Wilber, 198I, 2000).

\section{Limitations of the study}

The relatively small samples were a limitation, and quantitatively speaking this prevented the study from making firm generalised inferences. As the sample "favoured" older and more educated participants, further randomised controlled studies with larger samples would be needed to make more transferable inferences. Other limiting factors were that the sample was representative of the ethnic spread in South Africa, included a preponderance of females over males, and participants with higher than average levels of education. More in depth qualitative outcome evaluation could have been included.

With the benefit of hindsight, perhaps further research in this area of interest should be directed along the following lines, aiming to explore whether yoga therapy may serve as a viable alternative to medication for the control of anxiety. The basic design would be as follows; secure commitment from a more substantial sample group who were in circumstances that are likely to induce anxiety, perhaps a volunteer group of honours students who may be registered for various courses; randomly allocate experimental and control groups, administer a test that is sensitive to the measurement of anxiety, as part of a broader battery of tests, aimed at "masking" the true intention of the test; secure the commitment from a significant portion of the sample to attend yoga classes for a given period of time; administer tests at the conclusion of the period.

While it may be a tall order to secure a test group that would spend time on yoga, an approach along these lines would have the effect of "filtering out" the seasoned students of yoga who perhaps have reaped the benefits of practising it, or who have preconceived views on its effects. Owing to such various limitations especially with regard to sample size, further research is necessary.

\section{Conclusion}

Despite the non-significant differences between the groups, and that the quantitative effect mitigates against definite causal inferences, as a whole the quantitative and qualitative findings indicate a significant link between yoga practice and alleviation of anxiety, suggesting that yoga therapy has the potential to reduce levels of perceived anxiety on numerous levels. The significant quantitative within-group experimental effect and definitive qualitative findings supported the hypothesis of this research, that is, that regular yoga therapy was effective in terms of decreasing perceived anxiety levels within the participants.

The participants specifically indicated that their yoga practice provided them with noticeable relief from anxiety, improved physical well-being, contentment, relaxation, breath control, mindfulness, transcendence and spirituality. They emphasised focus in the present moment, consciousness of their breathing, and relaxation. Patanjali's philosophical principles of yogic life practice were an encouragement to live ethical, healthy and spiritual lives. This study therefore provided empirical evidence for yoga therapy as a valuable and potentially cost effective treatment intervention for decreasing perceived anxiety. However, in view of various limitations, especially with regard to small sample size, further research with larger numbers of participants is needed.

\section{References}

Beck, A. T., \& Steer, R. A. 1993. Beck Anxiety Inventory. San Antonio, TX: Harcourt Brace.

Boyatzis, R. E. 1998. Transforming Qualitative Information: Thematic Analysis and Code Development. Thousand Oaks: Sage.

Chopra, D., \& Simon, D. 2004. The Seven Spiritual Laws of Yoga. Hoboken, NJ: Wiley.

Da Silva, T. L., Ravindran, L. N., \& Ravindran, A. V. 2009. Yoga in the Treatment of Mood and Anxiety Disorders: A Review. Asian Journal of Psychiatry, 2(I), 6-16. 
De Vos, A. S., Strydom, H., Fouche, C. B., \& Delport, C. S. L. 2008. Research at Grass Roots: for the Social Sciences and Human Service Professions ( $3^{\text {rd }}$ ed.). Pretoria: Van Schaik Publishers.

Forbes, B., Akturk, C., Cummer-Nacco, C., Gaither, P., Gotz, J., Harper, A., \& Hartsell, K. 2008. Yoga Therapy in Practice: Using Integrative Yoga Therapeutics in theTreatment of Comorbid Anxiety and Depression. [Electronic version]. InternationalJournal of Yoga therapy, 18, 87-95.

Gilbert, C. 1999. Yoga and Breathing. Journal of Bodywork and Movement Therapies, 3(1), 44-54.

lyengar, B. K. S. 1982. Light on Yoga. London: Unwin Paperbacks.

Khan, P. A., Singh, B., \& Salman, K. A. 2005. The Role of Yoga in Anxiety Reduction. In G. Shankar (Eds.), Psychotherapy, Yoga \& Spirituality (pp. 239-246). New Delhi: Jagdamba Publishing Company.

Pillay, A. L., Edwards, S. D., Sargent, C., \& Dhlomo, R. M. 200I. Anxiety Among University Students in South Africa. Psychological Reports, 88, II82-II86.

Rybarczyk, B., DeMarco, G., DeLaCruz, M., Lapidos, S., \& Fortner, B. 200I. A Classroom Mind/Body Wellness Intervention for Older Adults with Chronic Illness:Comparing Immediate and I-year Benefits. Behavioural Medicine, 27, I5-27.

Sadock, B. J., \& Sadock, V. A. 2007. Synopsis of Psychiatry: Behavioural Sciences/Clinical Psychiatry. (10 th ed.). New York: Lippincott Williams \& Wilkins.

Shankar, S. 2006. Yoga Psychotherapy and its Applications. New Delhi: Satyam Publishing House.

Smith, C., Hancock, H., Blake-Mortimer, J., \& Eckert, K. A. 2007. A Comparative Trial of Yoga and Relaxation to Reduce Stress and Anxiety. Journal of AustralianTraditional-Medicine Society, I5(4), 77-83.

Streeter, C. C., Jensen, J. E., Perlmutter, R. M., Cabral, H. J., Tian, H., Terhune, D. B., Ciraulo, D. A., \& Renshaw, P. F. 2007. Yoga Asana Sessions Increase Brain GABA Levels: A Pilot Study. The Journal of Alternative and Complementary Medicine, I3(4), 4I9426.

Streeter, C. C., Whitfield, T. H., Owen, L., Rein, T., Karri, S. K., Yakhkind, A., Perlmutter, R., Prescot, A., Renshaw, P. F., Ciraulo, D. A., \& Jensen, J. E. 20I0. Effects of Yoga Versus walking on Mood, Anxiety, and Brain Levels: A Randomised Controlled MRS Study. The Journal of Alternative and Complementary Medicine, I6(I I), II I5- I I 52.

Wilber, K. 198I. No Boundary: Eastern and Western Approaches to Personal Growth. London: Shambhala.

Wilber, K. 1998. The Essential Ken Wilber. London: Shambhala.

Wilber, K. 2000. Integral Psychology. Boston: Shambhala.

Young, W. 1988. To Steady the Flame. Durban: Unity Publications. 